\title{
Cervical Incompetence: Modern Clinical Protocols and Real Practice
}

\author{
${ }^{1}$ Larisa D Belotserkovtseva, ${ }^{2}$ Ludmila V Kovalenko, ${ }^{3}$ Sergey E Ivannikov, ${ }^{4}$ Gulnora T Mirzoeva, ${ }^{5}$ Tatiana G Petrova
}

\section{ABSTRACT}

Objective: The objective is to evaluate efficiency of using internal protocol of prophylaxis preterm birth (PB).

Materials and methods: Three hundred and seventy gravidas without clinical symptoms of preterm delivery with cervical canal length of $<25 \mathrm{~mm}$ and on $<21$ gestation weeks were inspected. Protocol included anamnesis research, $200 \mathrm{mg}$ of daily vaginal progesterone, ultrasound monitoring of length and shape of cervical canal, and distinguished treatment of cervical insufficiency using cerclage or cervical pessary.

Results: Gravidas whose protocol was fully attended have more than dual-fold decrease of extra early preterm delivery risk ratio [ 4.3 vs $12.3 \%$ relative risk (RR) $0.47 ; 95 \%$ confidence interval $(\mathrm{Cl})$ 0.23-0.99], compared with those whose protocol was attended fractionary. Quantity of unprompted miscarriages in $22^{+0}$ week period also decreased dual-fold (6.6 vs $13.8 \%$; RR $0.47 ; 95 \% \mathrm{Cl} 0.23-0.99)$. The most common mistakes were ignorance of anamnesis data, wrong choice of ways of correction cervical insufficiency, long and ineffective treatment of genital tract infections, and inaccurate estimation of cervical canal.

Summary: Usage of effective medication, development of new clinical protocols, and detailed abidance of earlier accepted protocols, mistakes' analysis, and staff training are reserves of extremely PB decrease.

Keywords: Cervical cerclage, Cervical incompetence, Cervical pessary, Clinical protocol, Preterm delivery, Ultrasound cervicometry.

How to cite this article: Belotserkovtseva LD, Kovalenko LV, Ivannikov SE, Mirzoeva GT, Petrova TG. Cervical Incompetence: Modern Clinical Protocols and Real Practice. Donald School J Ultrasound Obstet Gynecol 2017;11(3):203-209.

Source of support: Nil

Conflict of interest: None

${ }^{1,2}$ Professor, ${ }^{3}$ Associate Professor, ${ }^{4,5} \mathrm{Head}$
${ }^{1,3}$ Department of Obstetrics, Gynecology and Perinatology
Institute of Medicine, Surgut State University, Surgut, Russian
Federation
${ }^{2}$ Institute of Medicine, Surgut State University, Surgut, Russian
Federation
${ }^{4}$ Department of Obstetrics Pregnancy Failure, Surgut Clinical
Perinatal Center, Surgut, Russian Federation
${ }^{5}$ Department of Ultrasound Inspection, Surgut Clinical Perinatal
Center, Surgut, Russian Federation

Corresponding Author: Larisa D Belotserkovtseva, Professor Department of Obstetrics, Gynecology and Perinatology Institute of Medicine, Surgut State University, Surgut, Russian Federatione-mail: glav_kpc@admsurgut.ru

\section{INTRODUCTION}

Frequency of PB rises almost in all countries in the world, making nowadays more than $10 \%$ of all deliveries. Prematurity and complications connected with it are the main reasons of neonatal death rate (during first 4 weeks of life) and are also the second most important reason of pneumonia death rate among children under the age of $5 .{ }^{1}$ There are a lot of reasons for $\mathrm{PB}$, and not all of them are quite obvious. At the same time, factors, such as burden reproductive history (unprompted $\mathrm{PB}$ in anamnesis or usage of auxiliary reproductive technologies) $)^{2,3}$ and shortening of uterine cervix (cervical insufficiency $)^{4,5}$ are very important in causing $\mathrm{PB}$.

Confidence interval with little frequency in population (about $1 \%$ ) is estimated as significant threat by many researchers. ${ }^{5-7}$ According to Heath VC $(1998)^{5}$ length of uterine cervix on $23 \mathrm{rd}$ gestation week, i.e., $\leq 15 \mathrm{~mm}$ is encountered in $<2 \%$ of all pregnancies ( 43 of 2,567 ); meanwhile, these gravidas are approximately 90 and $60 \%$ of all amount of women with unprompted PB in accordance with $<28$ and $<32$ weeks gestation period. ${ }^{5}$ Sizing length of cervical canal among gravidas, who gained PB treatment, allowed distinguishing vera and spuria labor: Unprompted delivery within 7 days happened to $40 \%$ of those who had cervical canal length $<14 \mathrm{~mm}$, and to $<1 \%$ of those whose cervical canal length was $>15 \mathrm{~mm} .{ }^{6}$ Length of uterine cervix $\leq 25 \mathrm{~mm}$ is positively connected with earlier gestation age during repeated $\mathrm{PB}$ in $<37,35,34$, and 32 weeks of gestation period. ${ }^{7}$

Precise supersonic sizing of uterine cervix has reverse casualty with PB risk. ${ }^{8}$ The most precise method of sizing length of cervical canal is usage of transvaginal supersonic detector. Patients must have empty urinary bladder; vaginal detector must be put in front arch of vagina in order to minimize pressure on uterine cervix as long as it increases cervix's length. Length of cervical canal should be measured straight from external to internal mouth of uterine cervix. Since state of uterine cervix is dynamic, it is needed to accomplish three measures within 5 minutes $^{5}$ (Fig. 1).

When $\mathrm{CI}$ is disclosed, there are several ways of prophylaxis of preterm delivery: Progesterone usage, cervical cerclage, or obstetrics pessary. Systematic review by Dodd et al, ${ }^{9}$ which was published in 2013 , summarized positive 


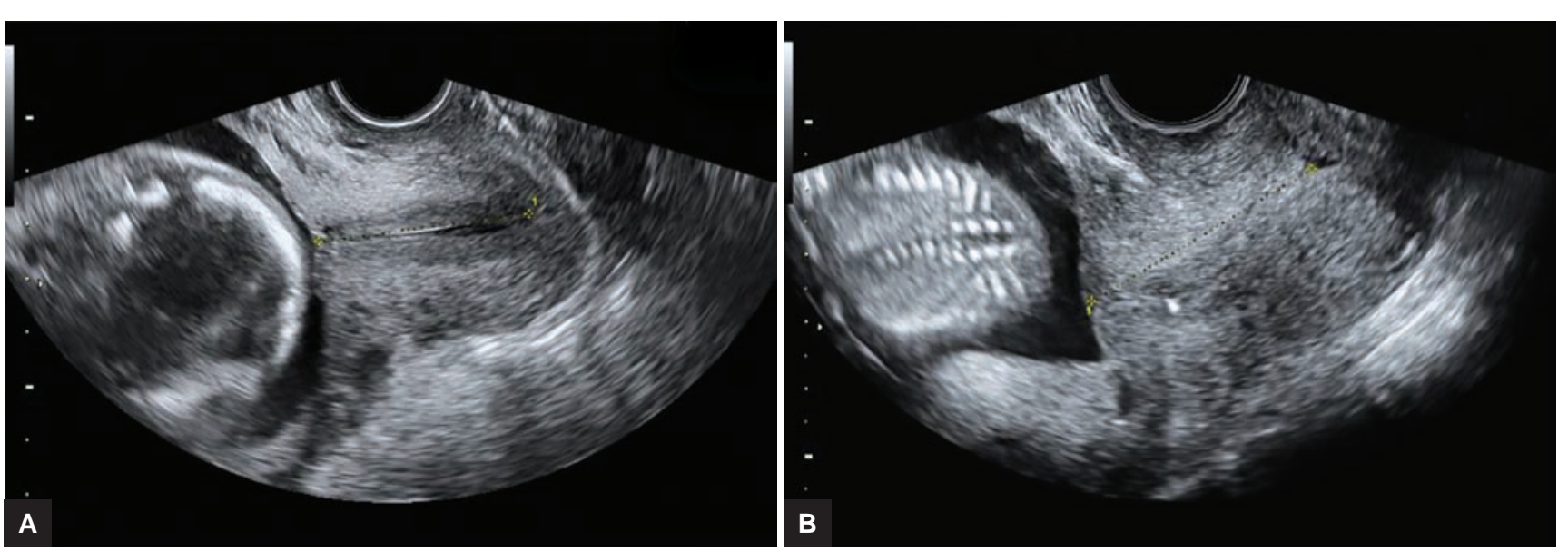

Figs $1 \mathrm{~A}$ and $\mathrm{B}$ : Cervicometry of non state

effects of progesterone. For example, among women with shortened uterine cervix (disclosed via ultrasound investigation) compared with placebo, progesterone associated with statistically authentic decrease risk of PB in period before 34 weeks (RR 0.64, 95\% CI 0.45-0.90) and 28 weeks (RR 0.59, 95\% CI 0.37-0.93). In group of women with unprompted PB in anamnesis usage of progesterone compared with placebo led to statistically authentic decrease risk of perinatal death (RR 0.50, 95\% CI 0.33-0.75) with PB before 34 weeks (RR 0.31, 95\% CI 0.14-0.69), transfer neonates in intensive care unit (RR $0.24,95 \%$ CI 0.14-0.40), and usage of artificial pulmonary ventilation (RR 0.40, 95\% CI 0.18-0.90).

Grounds for CI correction are not detailed nowadays and data about its efficiency are controversial. For instance, the research of Nicolaides et $\mathrm{al}^{10}$ showed low effectiveness of cervical cerclage in cases of shortened uterine cervix. Berghella et $\mathrm{al}^{11}$ in contrast, reported about significant decrease of quantity of $\mathrm{PB}$ in $<35$ weeks period, during usage of cerclage among gravidas with uterine cervix length $<25 \mathrm{~mm}$ and PB in anamnesis. Some specialist consider that cerclage usage can be more vital to decrease PB quantity than progesterone usage. ${ }^{12}$

Cervical incompetence correction via pessary is a simple and less-invasive procedure, which does not require anesthesia and can replace cervical cerclage surgery. Goya et $\mathrm{al}^{13}$ did randomized clinical research among 358 gravidas with uterine cervix length $\leq 25 \mathrm{~mm}$ and gestation period from 18 to 22 weeks. Pessary usage (192 women) leads to statistically significant decrease of PB both in $<37$ weeks gestation period and in $<34$ weeks (22 vs 59\%; RR 0.36, 95\% CI 0.27-0.49) and (6 vs 27\%, RR $0.24 ; 95 \%$ CI $0.13-0.43)$ respectively compared with expectant management. At the same time, measurable reduction of neonatal help expenses was mentioned in group, which used pessary compared with group, where pessary was not used.
Meanwhile, in a randomized clinical research by Hui et al $^{14}$ prophylaxis usage of cervical pessary did not reduce the decrease of $\mathrm{PB}$ quantity in period $<34$ weeks among obscure Chinese women with low-risk singlet pregnancy and uterine cervix length $<25 \mathrm{~mm}$ in 20 to 24 weeks gestation period.

Diversity of data leads to usage of different patient management protocols among connatural patient category. Comparison of three management guidelines of women with singlet pregnancy, PB in $<34$ weeks in anamnesis, and shortened uterine cervix showed congenial perinatal outcomes. ${ }^{15}$ This research included 142 women with cerclage (USA), 59 who got vaginal progesterone (UK), and 42 with cervical pessary (Spain).

Therefore, the choice of optimal way of managing patients with $\mathrm{CI}$ is an issue that needs discussion nowadays. In every facility, choice of optimal management is predicated upon its own policy, results, and developed management guidelines.

The objective of this research is to evaluate efficiency of usage of internal preterm delivery prophylaxis protocol. Research was made at the premises of Surgut Clinical Perinatal Center (SCPC) from January 2011 to December 2014. The SCPC is a huge regional health facility with annual delivery quantity more than 9,000. Share of preterm delivery was 6.1\% in 2014 .

Clinical protocol of prophylaxis of $\mathrm{PB}$ is implemented since 2011. ${ }^{16}$ Key statements of protocol are:

- Detachment of risk group with PB based on presence of unprompted termination of pregnancy in gestation period from $14^{+0}$ to $33^{+6}$ weeks, previous cerclage in cases of asymptomatic shortening, dilation of uterine cervix, and with three or more cases of curettage of uterine cavity in anamnesis.

- Sizing of length and shape of cervical canal via transvaginal ultrasound investigation among gravidas without risk factors in gestation period of 12 to 14 and 18 to 21 weeks and in gravidas with risk and 


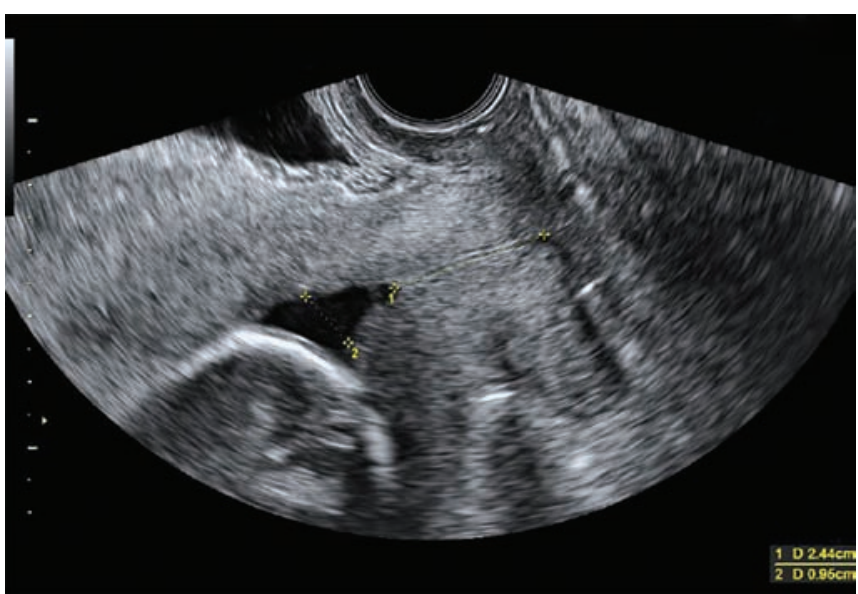

Fig. 2: Shortening of cervical canal's length, V-shaped widening of internal mouth

who have weekly monitoring in gestation period from 14 to 18 weeks.

- Prescription of vaginal progesterone (200 mg capsules of micronized progesterone in PB risk group).

- In case of disclose of shortening of cervical canal $<25$ $\mathrm{mm}$ before 22rd week, several options are used:

- Inspection of presence of urogenital infection, and treatment given if necessary;

- Cerclage for high-risk group;

- Cervical pessary if anamnesis does not include miscarriage;

- Prescription of vaginal progesterone.

- Ultrasound control is not required after CI correction.

- Removal of cerclage suture or cervical pessary takes place in the period of 36 to 37 gestation weeks if there is no fetomaternal disease or in case of painful uterine retractions and changings of uterine cervix or bloodtinged discharge.

Research included 370 gravidas without pain complaints, with length of cervical canal $<25 \mathrm{~mm}$ in gestation period from $14^{+0}$ to $24^{+6}$ weeks.

Disregard criteria were cases of multiple pregnancy, preterm amenorrhea, beginning of preterm delivery, fetus with development anomalies, or ultrasound markers of chromosomal anomalies.

Estimation of condition of uterine cervix was made by certified specialists with usage of ultrasonic device Voluson E8 with transvaginal multifrequency detector based on common practice. There were estimations of closed part of cervical canal and condition of internal mouth (Fig. 2).

Pregnancy term is defined based on last menstruation and confirmed via ultrasonic inspection or only on ultrasound results if ultrasound gestation period inspection results are distinguished from menstrual term for more than 5 days.

All gravidas' anamnesis were scrutinized and complex clinic-laboratorial inspection was made in
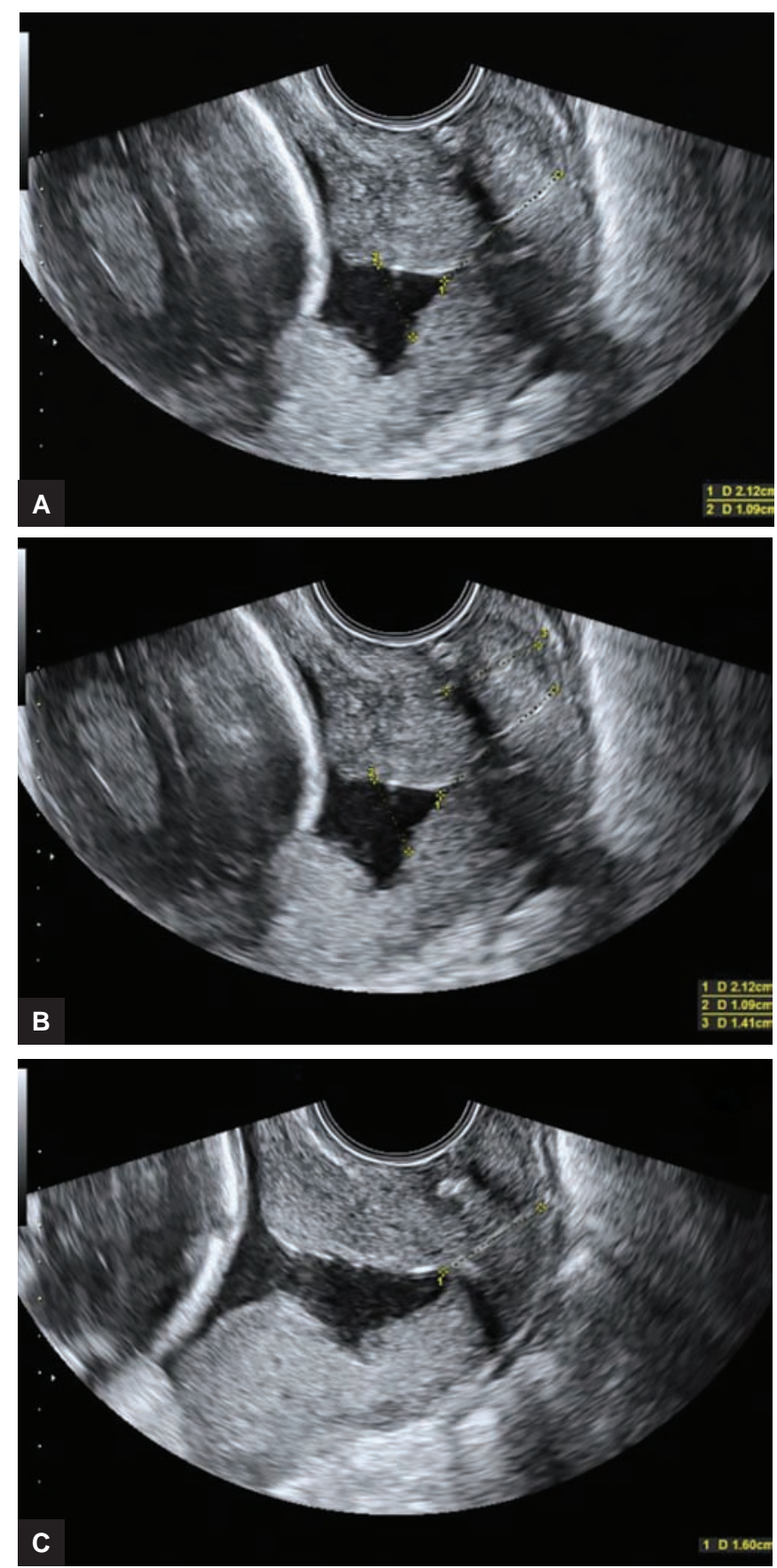

Figs 3A to C: Cervical incompetence in cerclage

order to disclose urogenital infection (microscopy of discharge of vagina and cervical canal, cervical smear, bacteriological inspection of discharge of cervical canal, molecular-biological inspection via multiplex real-time polymerase chain reaction for typing of bacterium ("Femoflor" test).

Decision of ways of CI correction was made in the light of received data. Cervical incompetence correction with usage of silicone cerclage obstetrics pessary by "Dr Arabin" was used with gravidas, whose anamnesis was not a burden. The same case in high-risk groups was solved by surgical correction via McDonald suture using nonabsorbable synthetic filament (Fig. 3). 
All clinical records were retrospectively scrutinized by experts in order to decide whether protocol was abided fully or fractionary. Sixty-five cases from 370 protocols were executed not in full measure. Comparison was made between gravidas whose protocols were executed both entirely and fractionary. Birth in $<37$ weeks was claimed as basic outcome. Secondary outcome was termination of pregnancy in term less than $22^{+0}$ weeks, unprompted delivery in term less than $28^{+0}$ and $32^{+0}$ gestation weeks, birth in time, and also weight of fetus at the birth, quantity of neonatal intensive care unit (NICU), and perinatal death.

Intragroup comparisons were made with usage of Fisher's exact test for quantitative variables. Chi-square test was used for qualitative variables. Furthermore, risk ratio and $95 \% \mathrm{CI}$ were calculated.

In order to compare duration of treatment in NICU, median line and interquartile interval were calculated in comparison groups; $\mathrm{p}<0.05$ was considered as statistically significant. All mathematical calculations were done via MS Excel.

\section{RESULTS AND DISCUSSION}

During the time of research, 370 gravidas with CI were disclosed. Demographical and clinical characteristics of gravidas who were involved in research are presented in Table 1. Average age of patients is about 30 years and has no significant differences between groups. Quantity of gravidas with weight deficit is about $5 \%$ and was quiet similar in comparison groups.

None of the significant differences on parity between comparison groups were disclosed. Special attention should be paid to high ratio of preterm delivery in anamnesis, habitual miscarriage, and frequency of immature birth in anamnesis of gravidas with CI. Disclosed risk factors ratify that CIs have entwinement with burden anamnesis.

Table 2 presents pregnancy outcomes in research group. Exposure of $\mathrm{CI}$ at the time of first screening assay raises a question about further management guidelines. Experience of our center leads to the fact that CI correction in risk group can result in carrying a pregnancy up to full term for more than two-thirds of gravidas. It can be seen that delivery in term $22^{+0}$ to $27^{+6}$ weeks happened in every 20th case, whether protocol abidance performed entirely or fractionary. Unprompted pregnancy termination in term $<22^{+0}$ weeks happened to $7.8 \%$ patients with CI. Results of group with fully performed protocol turned out to be the best for all gravidas involved in research.

However, such differences were disclosed in comparison between groups with fully or fractionary executed protocol. In groups with full protocol abidance, more than dual-fold decrease of risk ratio of extra early preterm delivery was noted (4.3 vs $12.3 \%$; RR 0.47 ;

Table 1: Demographic and clinical characteristics involved in research gravidas

\begin{tabular}{|c|c|c|c|}
\hline & $\begin{array}{l}\text { Full protocol } \\
\text { abidance }(n=305)\end{array}$ & $\begin{array}{l}\text { Fractionary protocol } \\
\text { abidance }(n=65)\end{array}$ & $\begin{array}{l}\text { Possibility of } \\
\text { differences }(p)\end{array}$ \\
\hline Age (years) & $28( \pm 4.9)$ & $27( \pm 4.6)$ & $>0.05$ \\
\hline Smoking & $14(4.6)$ & $4(6.1)$ & $>0.05$ \\
\hline BMI $\left(\mathrm{kg} / \mathrm{m}^{2}\right)$ & $22.3( \pm 4.9)$ & $22.3( \pm 3.5)$ & $>0.05$ \\
\hline $\mathrm{BMI}<18$ & $15(4.9)$ & $3(4.6)$ & $>0.05$ \\
\hline Nonparous & $174(57.0)$ & $36(55.3)$ & $>0.05$ \\
\hline Preterm delivery in anamnesis & $126(41.3)$ & $27(41.5)$ & $>0.05$ \\
\hline Two or more unprompted abortion after 14 weeks & $62(20.3)$ & $14(21.5)$ & $>0.05$ \\
\hline Curettage of uterine cavity in anamnesis & $203(66.5)$ & $40(61.5)$ & $>0.05$ \\
\hline Cervical canal length at diagnosis time & $19.1( \pm 5.8)$ & $16.9( \pm 5.8)$ & $>0.05$ \\
\hline Pregnancy term at diagnosis & $20.0( \pm 1.1)$ & $21.3( \pm 1.0)$ & $>0.05$ \\
\hline
\end{tabular}

Data presented as average (mean-square deviation) or as $\mathrm{n}(\%)$

Table 2: Influence of protocol abidance on delivery time

\begin{tabular}{lllll}
\hline Delivery time & Total $(n=370)$ & $\begin{array}{l}\text { Full protocol abidance } \\
(n=305)\end{array}$ & $\begin{array}{l}\text { Fractionary protocol } \\
\text { abidance }(n=65)\end{array}$ & $R R(95 \% \mathrm{Cl})$ \\
\hline$<22^{+0}$ weeks & $29(7.8)$ & $20(6.6)$ & $9(13.8)$ & $0.47(0.23-0.99)^{*}$ \\
$22^{+0}-27^{+6}$ weeks & $21(5.7)$ & $13(4.3)$ & $8(12.3)$ & $0.35(0.15-0.80)^{*}$ \\
$28^{+0}-36^{+6}$ weeks & $51(13.8)$ & $36(11.8)$ & $15(23.1)$ & $0.81(0.30-0.88)^{*}$ \\
$>37^{+0}$ weeks & $269(72.7)$ & $236(77.4)$ & $33(50.8)$ & $1.52(1.19-1.95)^{*}$ \\
\hline
\end{tabular}

Data presented as $\mathrm{n}(\%) ; \mathrm{RR}$ and $95 \% \mathrm{Cl}$ calculated between groups with full or fractionary protocol abidance, ${ }^{*}$ differences are statistically authentic 
Cervical Incompetence: Modern Clinical Protocols and Real Practice

Table 3: Fetus mass in cases of full or fractionary protocol abidance

\begin{tabular}{llll}
\hline & $\begin{array}{l}\text { Full protocol } \\
\text { Fetus weight } \\
\text { abidance } \\
(n=305)\end{array}$ & $\begin{array}{l}\text { Fractionary } \\
\text { protocol } \\
\text { abidance } \\
(n=65)\end{array}$ & $R R(95 \% \mathrm{Cl})$ \\
\hline$<500$ & $20(6.6)$ & $9(13.8)$ & $0.47(0.23-0.99)^{*}$ \\
$500-999$ & $10(3.3)$ & $7(10.8)$ & $0.30(0.12-0.77)^{*}$ \\
$1,000-1,500$ & $11(3.0)$ & $5(7.6)$ & $0.47(0.17-1.3)$ \\
$1,500-1,999$ & $9(3.0)$ & $6(9.2)$ & $0.32(0.12-0.87)^{*}$ \\
$>2,000$ & $255(83.6)$ & $38(58.5)$ & $1.43(1.16-1.77)^{*}$ \\
\hline
\end{tabular}

Data are presented as $n(\%)$, ${ }^{*}$ differences are statistically authentic

95\% CI 0.23-0.99). Quantity of unprompted pregnancy termination in term $<22^{+0}$ weeks also decreased more than dual-fold (6.6 vs 13.8\%; RR 0.47; 95\% CI 0.23-0.99). Such tendency remained in every researched interval. Statistically authentic data from term $28^{+0}$ to $36^{+6}$ between two groups with fully or fractionary protocol abidance were achieved (11.8 vs $23.1 \%$; RR 0.81 ; $95 \%$ CI $0.30-0.88$ ). In case of fractionary protocol abidance, quantity of delivery in term $>37$ weeks decreases by one-third (77.4 vs 50.8\%; RR 1.52; CI 1.19-1.95).

Weight of newborn is one of the key factors that influences perinatal morbidity and death rate. As presented in Table 3, newborn weight $<1,000,1,500,2,000$ gm much more frequently appears in cases of fractionary protocol abidance. Newborns' weight has distinct correlation with gestation period and confirms importance of scrutinous performance of clinical protocol.

Process of improving situation was gradual: Exposure and grading of mistakes, staff training, supervise on protocol abidance, and detailed case study of every extra early preterm delivery accident. Frequency of different mistakes is presented in Table 4 .

Most frequent mistake was not including patient in risk group according to anamnesis. This mistake led to absence of both vaginal progesterone prescription and monitoring cervical canal length from 14 to 18 weeks. It results either in unprompted pregnancy termination or late treatment in worse conditions (Fig. 4).

Next on frequency rate mistake is wrong choice of ways of CI correction: Nonuse of cerclage for gravidas with burden anamnesis and nonuse of cervical pessary for gravidas with exposed shortening of cervical canal. Another serious problem is prevalence of genital system infections. Long and ineffective treatment genital tract infection of gravidas, whom needed surgical correction of cervical incompetence led to protract necessary treatment.

Mistakes within ultrasound inspection also can be mentioned as reason of failure, while other mistakes are connected with wrong sizing of cervical canal length and wrong interpretation of its shape (Fig. 5).
Table 4: Frequency of mistake occurrence during management of gravidas with $\mathrm{Cl}$ according to delivery time

\begin{tabular}{|c|c|c|c|c|}
\hline \multirow[b]{2}{*}{ Exposed mistakes } & \multicolumn{4}{|c|}{ Delivery time } \\
\hline & $\begin{array}{l}<22^{+0} \\
\text { weeks } \\
(n=9)\end{array}$ & $\begin{array}{l}22^{+0}-27^{+6} \\
\text { weeks } \\
(n=8)\end{array}$ & $\begin{array}{l}28^{+0}-36^{+6} \\
\text { weeks } \\
(n=15)\end{array}$ & $\begin{array}{l}>37^{+0} \\
\text { weeks } \\
(n=33)\end{array}$ \\
\hline $\begin{array}{l}\text { Risk group was } \\
\text { not disclosed from } \\
\text { anamnesis }\end{array}$ & 5 & 7 & 7 & 11 \\
\hline $\begin{array}{l}\text { Wrong choice of } \\
\text { correction method }\end{array}$ & 3 & 5 & 3 & 9 \\
\hline $\begin{array}{l}\text { Irrational treatment } \\
\text { of genital system } \\
\text { infections }\end{array}$ & 3 & 4 & 4 & 8 \\
\hline $\begin{array}{l}\text { Incorrect supersonic } \\
\text { inspection }\end{array}$ & 2 & 2 & 3 & 5 \\
\hline
\end{tabular}

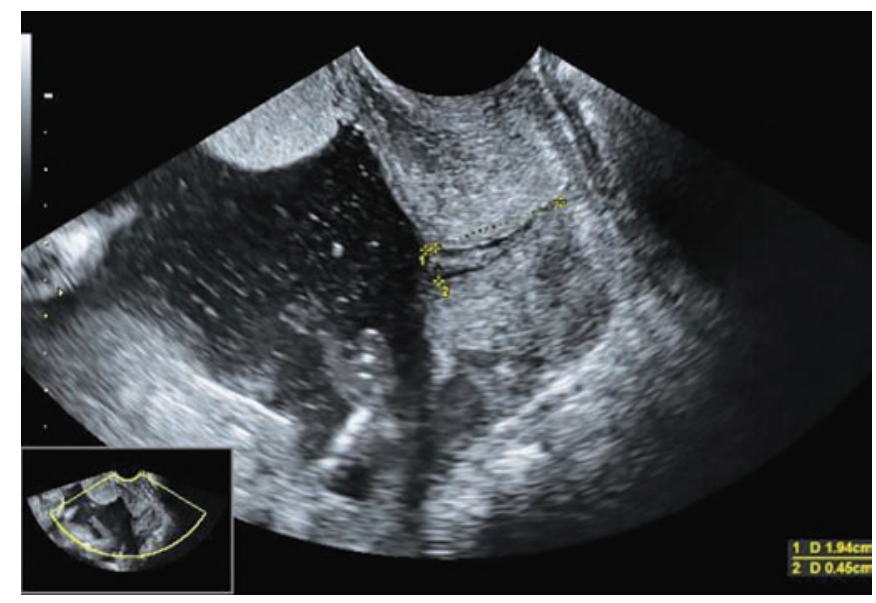

Fig. 4: Cervical incompetence

Worst conceivable accident is combination of several mistakes in one patient's case. It mostly happened with gravidas, who had extra early preterm delivery according to our data. It shows the following clinical case.

Gravida M, 36 years old, was admitted to hospital on September 24, 2012 in pregnancy term of $19^{+2}$ weeks, with first-time exposure of cervical canal's shortening down to $24 \mathrm{~mm}$. Anamnesis contained information about five artificial abortions, sixth pregnancy's ending with spontaneous abortion on 19th week in the setting of fetal bladder prolapse and premature amenorrhea. Proving ultrasonic inspection exposed shortening of cervical canal down to $11.3 \mathrm{~mm}$ and its U-shape widening (Fig. 6).

Correction via cervical pessary and vaginal progesterone took place. Premature amenorrhea happened on $22^{+2}$ term. On $22^{+4}$ week term dead fetus (560 gm) delivery happened.

Analysis of this case shows combination of typical mistakes, such as lack of attention for burden anamnesis, wrong choice of CI correction method, and incorrect ultrasound inspection. 


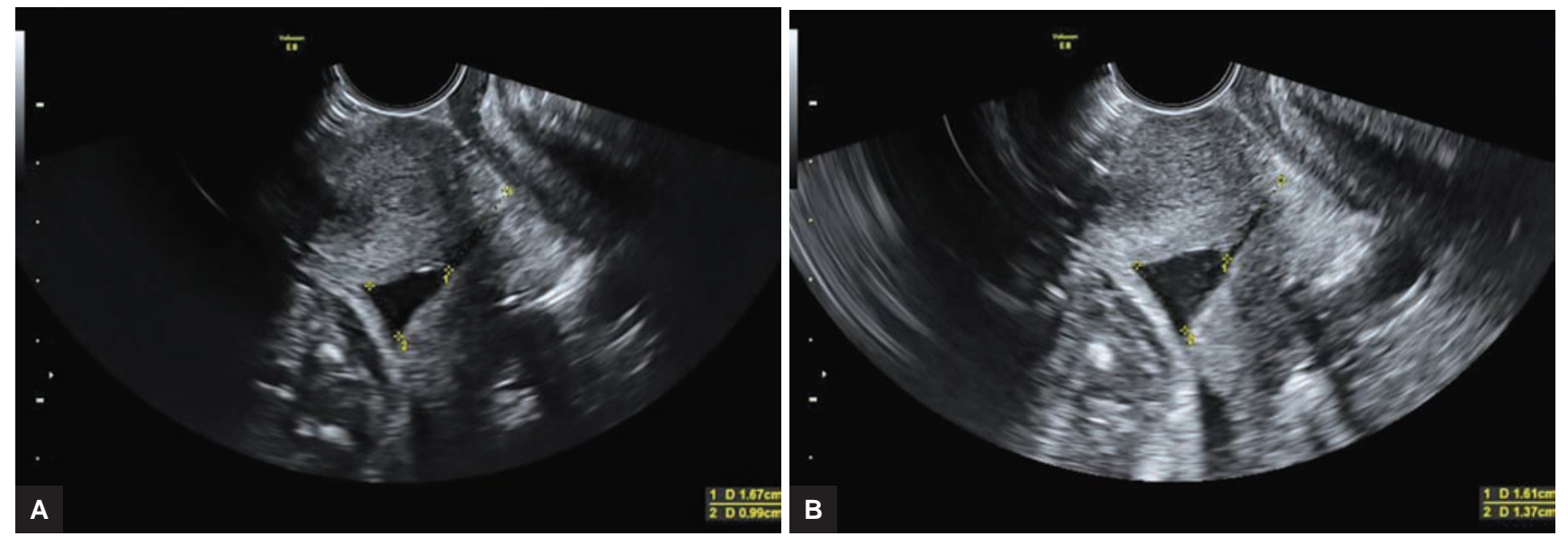

Figs 5A and B: Critical cervical incompetence
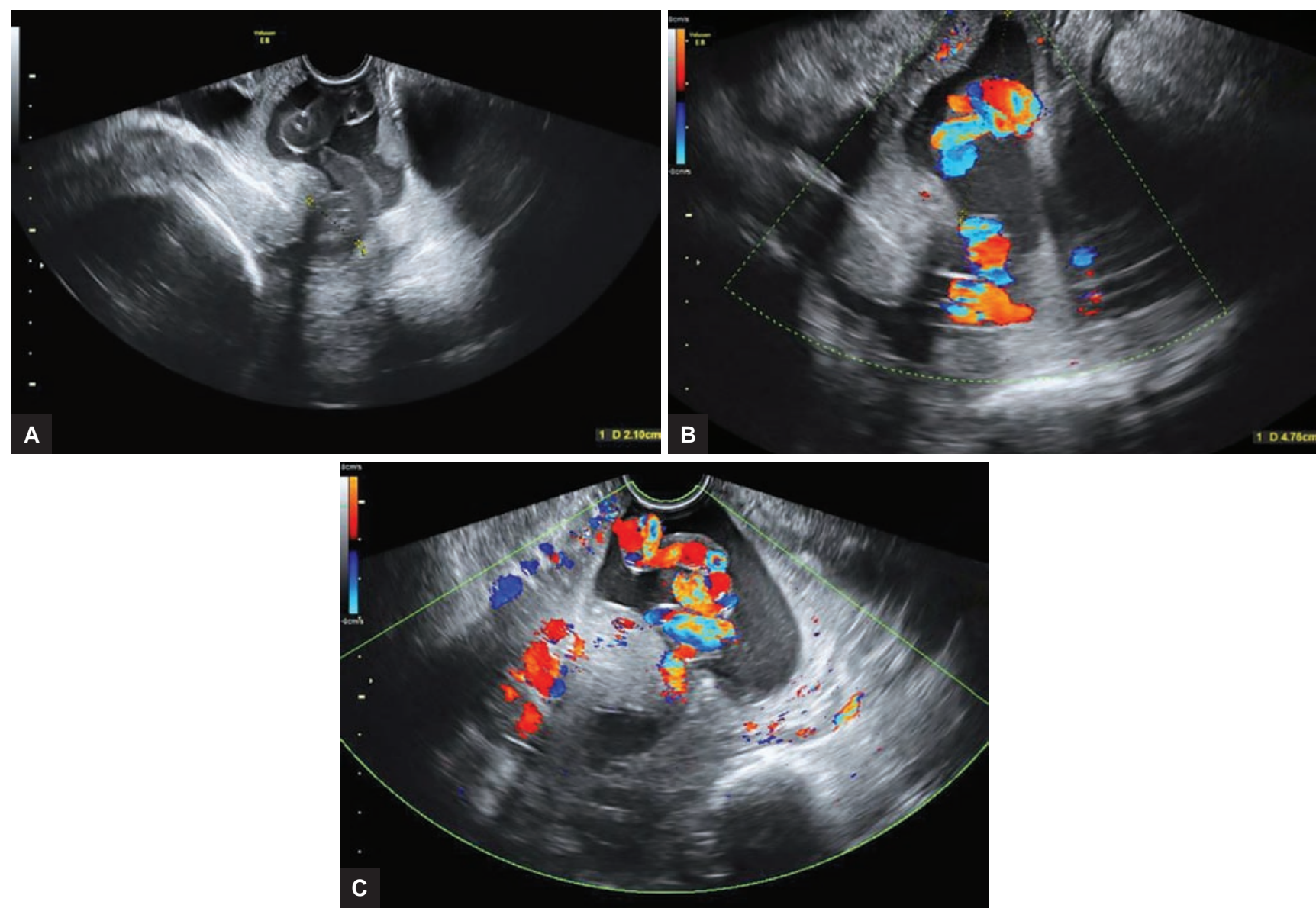

Figs 6 A to C: Umbilical cord prolapse of fetal bladder (gestation term $22^{+1}$ )

In 2014, same patient from early term of next pregnancy was prescribed vaginal progesterone, and on $15^{+5}$ term cervical cerclage was made. It resulted in conservative delivery on $39^{+5}$ term and fetus weight $4010 \mathrm{gm}$ and 8 to 9 Apgar score.

Our activity about reducing mistakes' quantity in gravidas with $\mathrm{CI}$ treatment resulted in decrease of mistakes' occurrence in 2014, compared with previous years. Table 5 contains comparative data from 2012 to 2014. Attained results show reduction of quantity of extra early preterm delivery.
That reduction is not clinically significant, because it is only $2 \%$. But this reduction happened in the setting of absence of managing mistakes in most difficult clinical group, when fetus outlook is hard to predict.

\section{SUMMARY}

Both usage of effective medication or new clinical protocol development and scrutinous abidance of conventional protocols, mistakes' examination, and staff training can be claimed as reserve for decreased quantity of extra early preterm birth. 
Table 5: Comparison of delivery date and quantity of exposed departures from clinical protocol in 2012 and 2014

\begin{tabular}{|c|c|c|c|c|c|c|c|c|}
\hline & \multicolumn{2}{|c|}{$<22^{+0}$ weeks } & \multicolumn{2}{|c|}{$22^{+0}-27^{+6}$ weeks } & \multicolumn{2}{|c|}{$28^{+0}-36^{+6}$ weeks } & \multicolumn{2}{|c|}{$>37$ weeks } \\
\hline & Cases n (\%) & $\begin{array}{l}\text { Mistakes } \\
n(\%)\end{array}$ & Cases n (\%) & $\begin{array}{l}\text { Mistakes } \\
n(\%)\end{array}$ & Cases n (\%) & $\begin{array}{l}\text { Mistakes } \\
n(\%)\end{array}$ & Cases n (\%) & $\begin{array}{l}\text { Mistakes } \\
n(\%)\end{array}$ \\
\hline $2012(n=87)$ & $8(9.2)$ & $7(87)$ & $5(5.7)$ & $5(100)$ & $13(14.9)$ & $9(69.2)$ & $61(70.1)$ & $10(16.3)$ \\
\hline $2014(n=107)$ & $5(4.7)$ & $1(20)$ & $4(3.7)$ & $0(0)$ & $14(13.1)$ & $3(21.4)$ & $84(78.5)$ & $3(3.6)$ \\
\hline
\end{tabular}

Percentage of number of cases calculated from 1 year, $\%$ of mistakes calculated from quantity of cases in group

\section{REFERENCES}

1. WHO. Born too soon: the global action report on preterm birth. In: Howson CP, Kinney MV, Lawn JE, editors. March of Dimes, PMNCH, Save the Children. Geneva: World Health Organization; 2012.

2. McManemy J, Cooke E, Amon E, Leet T. Recurrence risk for preterm delivery. Am J Obstet Gynecol 2007 Jun;196(6):576. e1-576.e7.

3. Allen VM, Douglas WR. Pregnancy outcomes after assisted reproductive technology. Joint SOGC-CFAS Guideline no. 173, March 2007. J Obstet Gynaecol Can 2006;173:222-233.

4. Robinson, JN.; Norwitz, E. Risk factors for preterm labor and delivery. 2007. [cited 2007 Dec 17]. Available from: http:// www.uptodate.com/contents / risk-factors-for-pretermlabor-and-delivery.

5. Heath VC, Southall TR, Souka AP, Novakov A, Nicolaides KH. Cervical length at 23 weeks of gestation: relation to demographic characteristics and previous obstetric history. Ultrasound Obstet Gynecol 1998 Nov;12(5):304-311.

6. Tsoi E, Akmal S, RaneS, Otigbah C, Nicolaides KH. Ultrasound assessment of cervical length in threatened preterm labor. Ultrasound Obstet Gynecol 2003 Jun;21(6):552-555.

7. Romero J, Rebarber A, Saltzman DH, Schwartz R, Peress D, Fox NS. The prediction of recurrent preterm birth in patients on 17-alpha-hydroxyprogesterone caproate using serial fetal fibronectin and cervical length. Am J Obstet Gynecol 2012 Jul;207(1):51.e1-51.e5.

8. Honest H, Bachmann LM, Coomarasamy A, Gupta JK, Kleijnen J, Khan KS. Accuracy of cervical transvaginal sonography in predicting preterm birth: a systematic review. Ultrasound Obstet Gynecol 2003 Sep;22(3):305-322.

9. Dodd JM, Jones L, Flenady V, Cincotta R, Crowther CA. Prenatal administration of progesterone for preventing preterm birth in women considered to be at risk of preterm birth. Cochrane Database Syst Rev 2013 Jul;7:CD004947.
10. To MS, Alfirevic Z, Heath VCF, Cicero S, Cacho AM, Williamson PR, Nicolaides KH, Fetal Medicine Foundation Second Trimester Screening Group. Cervical cerclage for prevention of preterm delivery in women with short cervix: randomised controlled trial. Lancet 2004 Jun;363(9424): 1849-1853.

11. Berghella V, Keeler SM, To MS, Althuisius SM, Rust OA. Effectiveness of cerclage according to severity of cervical length shortening: a meta-analysis. Ultrasound Obstet Gynecol 2010 Apr;35(4):468-473.

12. Chang HH, Larson J, Blencowe $\mathrm{H}$, Spong $\mathrm{CY}$, Howson $\mathrm{CP}$, Cairns-Smith S, Lackritz EM, Lee SK, Mason E, Serazin AC, et al. Preventing preterm births: analysis of trends and potential reductions with interventions in 39 countries with very high human development index. Lancet 2013 Jan;381(9862): 223-234.

13. Goya M, Pratcorona L, Merced C, Rodó C, Valle L, Romero A, Juan M, Rodríguez A, Muñoz B, Santacruz B, et al. Cervical pessary in pregnant women with a short cervix (PECEP): an open-label randomised controlled trial. Lancet 2012 May;379(9828):1800-1806.

14. Hui SY, Chor CM, Lau TK, Lao TT, Leung TY. Cerclage pessary for preventing preterm birth in women with a singleton pregnancy and a short cervix at 20 to 24 weeks: a randomized controlled trial. Am J Perinatol 2013 Apr;30(4):283-288.

15. Alfirevic Z, Owen J, Carreras Moratonas E, Sharp AN, Szychowski JM, Goya M. Vaginal progesterone, cerclage or cervical pessary for preventing preterm birth in asymptomatic singleton pregnant women with a history of preterm birth and a sonographic short cervix. Ultrasound Obstet Gynecol 2013 Feb;41(2):146-151.

16. Belotserkovtseva LD, Kovalenko LV, Ivannikov SE, Mirzoeva GT. Limitations of early diagnosis of cervical failure for prophylaxis of extremely preterm delivery. Veliky Novgorod (NovSU) 2015;85(2):117-124. 